\title{
Corrigendum
}

\section{Corrigendum to “A Multiview Formal Model of Use Case Diagrams Using $Z$ Notation: Towards Improving Functional Requirements Quality"}

\author{
Khadija El Miloudi (iD) and Aziz Ettouhami \\ LCS Laboratory, Faculty of Sciences of Rabat, Mohammed V University in Rabat, Rabat, Morocco \\ Correspondence should be addressed to Khadija El Miloudi; elmiloudi.khadija@gmail.com \\ Received 10 December 2019; Accepted 11 December 2019; Published 13 April 2020 \\ Copyright ( 2020 Khadija El Miloudi and Aziz Ettouhami. This is an open access article distributed under the Creative Commons \\ Attribution License, which permits unrestricted use, distribution, and reproduction in any medium, provided the original work is \\ properly cited.
}

In the article titled "A Multiview Formal Model of Use Case Diagrams Using Z Notation: Towards Improving Functional Requirements Quality" [1], there was an error in the affiliation "LCS Laboratory, Faculty of Sciences of Rabat, Mohamed V University in Rabat, Morocco" in which the spelling of "Mohammed" was incorrect. The corrected affiliation appears below, and in the author information above:

LCS Laboratory, Faculty of Sciences of Rabat, Mohammed V University in Rabat, Morocco

\section{References}

[1] K. El Miloudi and E. Aziz, "A multiview formal model of use case diagrams using $Z$ notation: towards improving functional requirements quality," Journal of Engineering, vol. 2018, Article ID 6854920, 9 pages, 2018. 